\title{
Review of: "2D inversion of electrical resistivity investigation of contaminant plume around a dumpsite near Onitsha expressway in southeastern Nigeria"
}

\author{
Alice Morita
}

Potential competing interests: The author(s) declared that no potential competing interests exist.

The study is interesting and of great importance nowadays, considering that inadequate waste disposal is still abundant in developing countries and has caused several impacts on soils, water resources and public health. The study focuses on environmental impacts of an unplanned waste deposit in Nigeria, which receives different types of waste, including hazardous ones, and is surrounded by residential areas, which gives the study a greater importance.

The study is comprehensive, correlating VES and ERT results and borehole data. The article gives a comprehensive background of other studies in the literature performing geoelectrical surveys, and gives a detailed description of geological, hydrological, hydrogeological and climatic conditions, permitting the comparison with other results from dumpsites around the world.

Nonetheless, I expected to find groundwater data so as to enable the determination of the level of contamination in the zones of geophysical anomalies. Even though the authors mention that groundwater studies will be the focus of future studies, they also affirm that groundwater is unfit for use as potable water, which is impossible to assume without physicochemical and microbiological analysis.

The location of profiles is not clear, and it should be presented in figures, such as in Figure 4, helping in the understanding of geophysical anomalies locations. I would also recommend to adopt, at least in one profile, larger electrode spacing so as to permit the investigation of deeper regions and evaluate the extent of the contaminant plume. I also expected to find more description of the waste deposit, such as the period it has been receiving waste, and the estimated amount of waste disposed of. Such information would help in understanding the extent of the contaminant plume.

Apart from the mentioned recommendations, I consider the article of excellent quality, contributing to the generation of information regarding contaminant behavior in different dumpsites around the world. 